\title{
livros
}
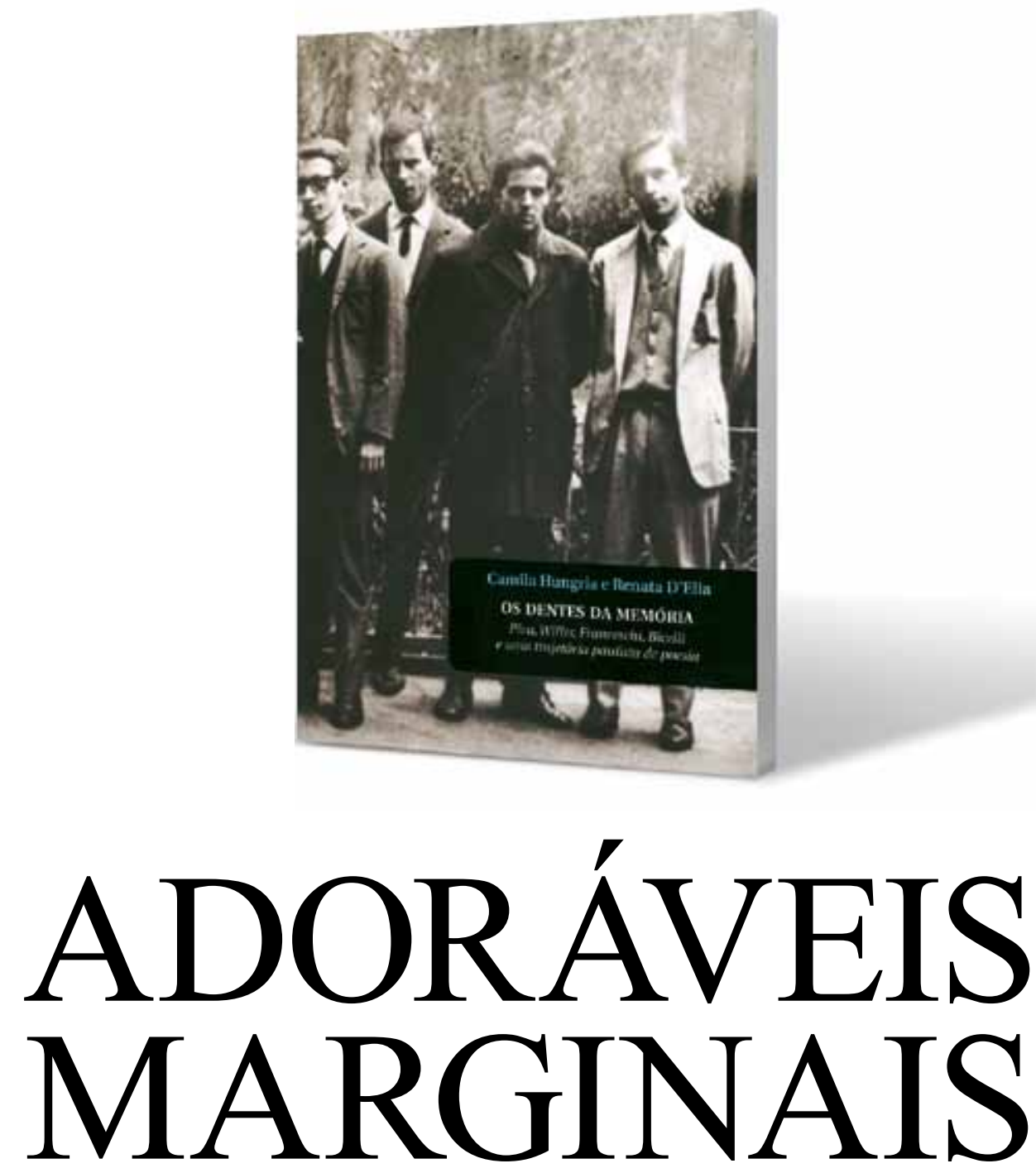

\section{Wilson Alves-Bezerra}

OS DENTES DA MEMÓRIA. PIVA, WILLER, FRANCESCHI, BICELLI E UMA TRAJETÓRIA PAULISTA DE POESIA, DE CAMILA HUNGRIA E RENATA D'ELIA, RIO DE JANEIRO, AZOUGUE, 2011, 255 P. 


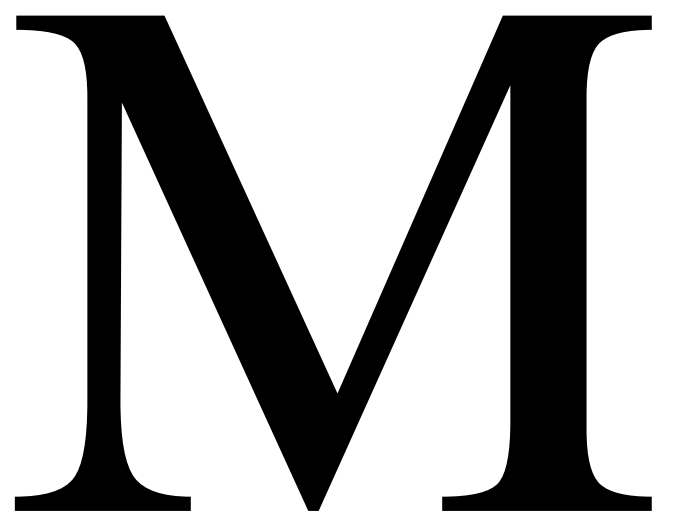

uitas antologias literárias publicadas ultimamente mostram, pela multiplicidade de projetos de escrita existentes, a dificuldade de seguir usando o termo geração literária. Cernir unidades parece tarefa vã quando a noção de literatura nacional também vai perdendo o sentido e suas tintas se esmaecendo. Pois o livro-reportagem de Camila Hungria e Renata D'Elia, sem lançar mão de recursos que não a palavra de um grupo de escritores e seus contemporâneos - os amigos, o editor, as namoradas -, trama a teia de relações de um grupo que já foi nomeado como "geração dos novíssimos", geração 60, poetas marginais, entre outros, e que inclui, de alguma forma, Roberto Piva (1933-2010), Claudio Willer, Antonio Fernando de Franceschi e Roberto Bicelli.

Piva teve, na última década, toda a sua obra relançada pela Editora Globo, em três belos volumes, o último deles com a gravação em áudio da voz do próprio autor, já debilitado mas ainda vigoroso, lendo poemas de toda a sua carreira. Willer, certamente o mais atuante entre eles, relançou sua obra poética pela Lamparina em 2004, e vem fazendo frequentes incursões na crítica acadêmica (como o lançamento de Um Obscuro Encanto, Gnose, Gnosticismo e a Poesia Moderna, Civilização Brasileira, 2010) e de divulgação (Geração Beat, L\&PM, 2009). De Franceschi, ganhador de alguns prêmios Jabuti na década de 80 por sua obra lírica, acaba de lançar nova coletânea de poemas, Sete Suítes, pela Companhia das Letras (2010).

Assim, a relevância do livro de Hungria e D’Elia consiste em trazer à luz as memórias e a palavra dessa geração de autores, em capturar essa "trajetória da poesia paulista", ocorrida antes da ditadura militar, num momento em que São Paulo, nas palavras de Willer, "ainda era província”. O livro é composto por vários depoimentos - tomados entre 2007 e 2010 - de cada um dos personagens. O mérito das repórteres foi o de tratar de alguns mesmos pormenores com todos os entrevistados, e depois intercalar as respostas, expondo concordâncias e contradições; no momento de organizar a trama, retiraram as perguntas. Assim, o que se tem é um longo diálogo forjado que dá ao leitor a impressão de uma longa conversa de reminiscências pessoais e geracionais, na qual se avança vertiginosamente - em meio a humor e contradições - da São Paulo dos anos 50 até os dias que correm. Ao fím do volume inclui-se um curto relato das autoras sobre Roberto Piva, no início de 2010, já hospitalizado e vivendo seus últimos dias.

Nesse sentido, a parte gráfica funciona como memória visual: o volume conta com um material precioso, que inclui resenhas de jornais e revistas brasileiras e estrangeiras, cuidadosamente reproduzidas de modo a possibilitar ao leitor sua leitura integral, fotos de arquivos pessoais e capas de livros. A "trajetória de poesia" assim concentrada, em texto e imagem, permite ao leitor ver como se formou aquele grupo de jovens vigorosos, exibidos nas primeiras fotos plenos e em poses desafiadoras, em seus paraísos literários e artificiais, tocando o horror cidade afora, lendo e escrevendo poesia noite adentro. Logo, o refluxo criativo com a entrada da idade adulta mostra como é duro à poesia resistir aos apelos mundanos da subsistência, à família, ao trabalho. E a parte final do livro mostra qual foi a resposta de cada um às contingências, e como se deu a reinvenção pessoal, trazendo no corpo as cicatrizes do tempo.

Figuras fundamentais tomam parte da conversa, como Massao Ohno, o editor independente que possibilitou que em 1961 muitos desses autores figurassem em sua Antologia dos Novíssimos, ou na então recém-lançada Coleção dos Novíssimos. Quem se interessa pela história editorial certamente encontra na figura de Ohno, filho de militar japonês, um nome sem o qual dificilmente teria se constituído uma geração de modo tão cabal. Intuitivo, Massao foi definido

\section{WILSON}

ALVES-BEZERRA é professor do Departamento de Letras da UFSCar, tradutor e autor de Reverberações da Fronteira em Horacio Quiroga (Humanitas/Fapesp). 
1 Piva fez parte da Antologia dos Novíssimos (1961), e teve ainda editado por Ohno os seguintes livros: $\mathrm{Pa}$ ranoia (1961), Piazzas (1964), Abra os Olhos e Diga Ah! (1975), 20 Poemas com Brócoli (1981).

2 De Willer, Ohno editou: Anotações Para um Apocalipse (1964), Dias Circulares (1976) e Jardins da Provocação (1981).

3 De Lima foram editados por Massao Ohno: Amore (1963) e Collage (1984).

4 Massao Ohno editou Hilst do começo de sua carreira até seus últimos anos: Trovas deMuitoAmorparaum Amado Senhor (1961), Sete Cantos do Poeta para o Anjo (1962), Da Morte. Odes Mínimas (1980), A Obscena Senhora D (1982), Cantares de Perda e Predileção (1983), Poemas Malditos, Gozosos e Devotos (1984), Sobrea TuaGrandeFace (1984), Amavisse (1989), O Caderno Rosa de Lori Lamby (1990),Bufólicas (1992), CantaresdoSem Nome e de Partidas (1995),DoAmor(1999).

5 De Pallottini, Ohno editou Esse Vinho Vadio (1988).

6 De Olga Savary, Ohno publicou: Sumidouro (1977),Altaonda (1979), Magma (1982), Linha D’Água (1987), Retratos (1989), Éden Hades (1994).

7 Figurou na Antologia dos Novíssimos (1961) e teve publicado o seu Motivos Alheios (1983).

8 Ohno editou Paisagem Doméstica (1984).

9 O historiador Istvan Janc só teve um poema seu figurando na Antologia dos Novíssimos (1961). por Carlos Vogt como "talvez o maior editor desorganizado que melhor contribuiu para organizar a poesia brasileira jovem durante pelo menos três décadas".

$\mathrm{O}$ fato é que passaram pelo prelo de Ohno autores tão diversos como podem ser Roberto Piva ${ }^{1}$, Claudio Willer ${ }^{2}$, Sérgio Lima ${ }^{3}$, Hilda Hilst ${ }^{4}$, Renata Pallottini ${ }^{5}$, Olga Savary ${ }^{6}$, Álvaro Alves de Faria ${ }^{7}$, entre muitos outros, como o próprio $\operatorname{Vogt}^{8}$ e o professor de história da USP Istvan Jancsó ${ }^{9}$ (1938-2010).

Quanto ao trabalho gráfico das obras publicadas por Ohno, é notório o cuidado e a inovação gráfica. Veja-se, por exemplo, o caso da parceria com o fotógrafo Wesley Duke Lee, recentemente falecido, responsável pelas imagens da São Paulo de Paranoia (1961), de Piva, e as ilustrações de Sete Cantos do Poeta para o Anjo (1962), de Hilst.

Os Dentes da Memória resgata parcialmente esse trabalho de vanguarda de Ohno, além de recuperar a história e os bastidores de um evento da cultura paulistana de caráter fundamental, do qual pouco se fala. Trata-se da Feira Paulista de Poesia e Arte, acontecida em novembro de 1976, no até então sagrado solo do Teatro Municipal de São Paulo, sob os auspícios de Sábato Magaldi, secretário municipal de Cultura à época. Os eventos ocorridos no Municipal soaram excessivos à sociedade paulistana, amansada pela ditadura havia anos e ouriçada pelos rumores do espetáculo do grupo musical Dzi Croquettes, além de performances radicais como a de um rapaz urinando no palco e, é claro, de leitura de poesia, exibição de filmes e exposição de artes plásticas. A gritaria foi generalizada, inclusive na imprensa, a tal ponto que o secretário Magaldi - que teve sua demissão pedida num editorial do Estadão - precisou vir a público, nas páginas do Jornal da Tarde, contextualizar e dar sentido ao que havia acontecido no Municipal.

Embora já tenha sido objeto do relato $\mathrm{Vol}$ ta, de Claudio Willer (Iluminuras, 1996), é com o apoio do registro jornalístico das fotos e jornais da época que o leitor de hoje pode ter uma ideia mais clara do alcance daquele evento, que foi qualificado por seus contem- porâneos como o primeiro movimento cultural de impacto ocorrido em São Paulo desde a Semana de Arte Moderna, de 1922. Cabe ressaltar que a promoção do evento esteve a cargo de Massao Ohno, e que foi inicialmente idealizado como um lançamento coletivo de 25 poetas. $O$ editor assim justificou a ideia da feira: "Era muita gente. Eu queria justamente me livrar do compromisso de lançar um por um. Tínhamos que beber muito em cada lançamento!” (p. 120).

Ainda está no livro, pungente, a recepção crítica dos livros fundamentais daqueles anos: Paranoia, de Roberto Piva, mescla visceral de Pauliceia Desvairada com Poeta em Nova Iorque, largamente comentado por seu próprio autor e contemporâneos. O mesmo cuidado é oferecido a Anotações para um Apocalipse, de Claudio Willer, e, na década de 70, ao livro de Bicelli, Antes que Eu Me Esqueça (1977), que também tem sua gênese recobrada. De Franceschi surge, tal como Bicelli, na condição de espectador de Piva e Willer naqueles primeiros anos, pois suas publicações só acontecem nos anos 80, pela Editora Brasiliense. Toninho Mendes, a certa altura, declara: "Todo mundo que nasceu junto com o Piva sofre do mal de ter nascido junto com o Piva, porque ele é o sol, e fica todo mundo rodando em volta. Ele é mais, ele tem mais peso, mais linguagem, mais sangue e mais vida" (p. 173).

Outras figuras importantes daquela época, como Jorge Mautner, Hilda Hilst e Orides Fontela, são mencionadas lateralmente ou fazem aparição meteórica, e deixam no leitor o desejo de ver aquela teia de relações ampliada para esses outros nomes, como forma de situá-los no contexto de então. De toda forma, a contribuição desse livro-reportagem é fundamental, por resgatar de modo documentado processo de escrita e circulação da poesia em São Paulo de um grupo tão singular. Até então, tinha-se muita reflexão sobre o movimento concreto, mas essa vertente mais visceral - que levou Piva a dizer que "não existe poesia experimental sem vida experimental" (p. 35) - de fato merecia ser mais bem iluminada. $\mathrm{O}$ curioso é perceber como 
esse grupo, que se constituiu e se sustentou à margem dos meios universitários, nos últimos anos vem recebendo da universidade seu processo de entrada no cânone: das teses acadêmicas dedicadas ao grupo às incursões de Claudio Willer na pós-graduação (atualmente cursa pós-doutoramento em Letras, na USP), vai se garantindo um lugar no circuito oficial.

De outra parte, percebe-se como, mais do que de uma geração, está se falando de um grupo de amigos, reunidos pelo gosto à poesia, mais até do que pela escrita. A máxima utilizada por De Franceschi em seu depoimento ao filme Uma Outra Cidade (2000), de Ugo Giorgetti, de que o que os uniu, acima dos credos literários, foi a amizade, parece se confirmar quase uma década depois. Inclusive a antologia de poemas dos quatro autores que fecha o volume se presta a mostrar, mais uma vez por palavras próprias, a estatura e o alcance diverso de cada um.

De Piva ficam suas imagens poéticas vigorosas, como esta do sol no fragmento do "poema com brócoli” em homenagem a Murilo Mendes:

"mestre Murilo Mendes tua poesia são os sapatos de abóboras que eu calço nestes dias de verão.

negócio de bruxas.

o sol caía na marmita

do adolescente na lavanderia.

você veria isso com seu olhar silvestre. um murro bem dado no vitral que eu [ mais adoro" (p. 198).

Willer, sempre provocativo, e que diz de si mesmo que tem "cabeça de ensaísta, não de poeta" (p. 177), comparece em fragmentos de ironia plena:

“vocês não entenderam nada, vocês não [sabem nada poesia não é querer escrever bem poesia é o que eu ainda vou relatar em [prosa poesia é o que eu ainda pretendo escrever [...]" (“A Palavra”, p. 218)
Bicelli comparece com um tom leve e bem-humorado, de poeta solar, que em determinada altura declarou de si mesmo, deixando clara sua opção de vida, que, "Se bebesse, faria teatro, publicidade e poesia. Mas prefiro beber pouco e manter meu corpinho de toureiro espanhol. Prefiro ficar na boa do que ser um poeta maldito, me foder e ficar com Alzheimer depois”. De Bicelli podem-se destacar os improváveis versos eróticos:

"lambeu-me a orelha até o ouvido virou de umbigo e gozou comigo veio ajudar-me a fazer a feira e administrar nossos bens. que mais posso dizer desse clima? nada, apenas que se ignore duas linhas

[acima" (p. 223).

De Franceschi é o poeta mais dissonante do grupo. Detentor de uma lírica que se opõe ao derramamento dos companheiros, opta pela contenção, e se mantém em torno a um objeto não nomeado no poema "Algo":

"há algo feito e acabado

que desmente a teoria

algo livre das aduanas

que flota justo e medido

no lírio das cumeeiras

algo subtraído das ganas

que se preserva intocado

algo entre as unhas

pelo tecido lunar

que te desconcerta e redime

algo certo algo errado

como inteiro domicílio

uns restos no copo

e a ressaca que volta

algo que é também soberba

e te ilumina

algo que não pode ser recuperado

por simples razão

teus mitos

como um quarto fechado

algo vertido na lâmina

que por descuido a corrói

algo sem gume nem corte

mas cujo toque dói” (p. 236). 